\title{
Antimicrobial Ionic Liquids with Fumarate Anion
}

\author{
Biyan He, Guangnan Ou, Changyi Zhou, Meihong Wang, and Suyan Chen
}

School of Bioengineering, Jimei University, Xiamen 361021, China

Correspondence should be addressed to Guangnan Ou; gnou@jmu.edu.cn

Received 2 May 2013; Accepted 29 July 2013

Academic Editor: Tomokazu Yoshimura

Copyright (C) 2013 Biyan He et al. This is an open access article distributed under the Creative Commons Attribution License, which permits unrestricted use, distribution, and reproduction in any medium, provided the original work is properly cited.

\begin{abstract}
The shortage of new antimicrobial drugs and increasing resistance of microbe to antimicrobial agents have been of some concern. The formulation studies of new antibacterial and antifungal agents have been an active research field. Ionic liquids are known as designed liquids with controllable physical/chemical/biological properties and specific functions, which have been attracting considerable interest over recent years. However, no attention has been made towards the preparation of ionic liquids with antimicrobial activities. In this paper, a new class of ionic liquids (ILs) with fumarate anion was synthesized by neutralization of aqueous 1-butyl-3-methylimidazolium hydroxide with equimolar monoester fumarate and characterized using NMR and thermal gravimetric analysis. The ILs are soluble in water and polar organic solvents and also soluble in the common ILs. The antimicrobial activities of the ILs are more active than commercially available potassium sorbate and are greatly affected by the alkyl chain length. The significant antimicrobial properties observed in this research suggest that the ILs may have potential applications in the modern biotechnology.
\end{abstract}

\section{Introduction}

Ionic liquids (ILs) are composed of bulky organic cations, for example, imidazolium or pyridinium, with a wide variety of anions including chloride $\left(\mathrm{Cl}^{-}\right)$, nitrate $\left(\mathrm{NO}_{3}^{-}\right)$, hexafluorophosphate $\left(\mathrm{PF}_{6}^{-}\right)$, and tetrafluoroborate $\left(\mathrm{BF}_{4}{ }^{-}\right)$. ILs are known as designed liquids with controllable physical/ chemical/biological properties and specific functions, which have been attracting considerable interest over recent years [1-8]. In 1996, Pernak and Skrzypczak reported, for quaternary alkylthiomethylimidazolium chlorides, the existence of a quantitative relation between critical micellar concentration and minimum inhibitory concentration against bacteria and the hydrophobicity index [4]. Later, the antibacterial activities of a series of imidazolium- and pyridinium-based ILs were reported [3, 9-13]. Demberelnyamba et al. [9] reported that the antibacterial and antifungal activities of quaternary imidazolium salts were greatly affected by their chain length, the type of substituted functional groups, and their position in the imidazolium ring. They found that all of the tested imidazolium halides that have two hydrophobic groups in the 1 and 3 positions in the imidazolium ring were the most suitable for antimicrobial activity. Also, the long alkyl chain imidazolium salts with methyl and hydroxyethyl substitution in the 2 and 3 positions of the imidazolium ring have an efficient antimicrobial activity. Pernak et al. synthesized protic ILs in the form of 1-alkyl- and 1-alkoxymethylimidazolium lactates and found that antimicrobial activities of the protic ILs are strongly related to the length of the substituent and to the type of anion [10].

Although there are intensive studies on the antimicrobial activities of ILs, much work is still needed to develop new types of antimicrobial ILs, especially the types with anions of antimicrobial activities. The shortage of new antimicrobial drugs and increasing resistance of bacteria to antimicrobial agents have been of some concern [14-16]. A number of research programs have been aimed at increasing the antimicrobial performances of molecules by introducing new molecular parameters such as heteroatoms [17-19], chemical functions [20,21], and aromatics [22, 23]. The formulation studies of new antibacterial and antifungal agents have been an active research field. Our strategy for antimicrobial ILs is to design ILs with organic acid anions. It was discovered that fumaric acid derivatives possess a broad spectrum activity against the growth of various microorganisms including fungi and bacteria [24, 25]. And fumaric acid esters exhibit antimicrobial activity far superior to those of propionic acid, propionates, sorbic acid, sorbates, benzoic acid, and the 


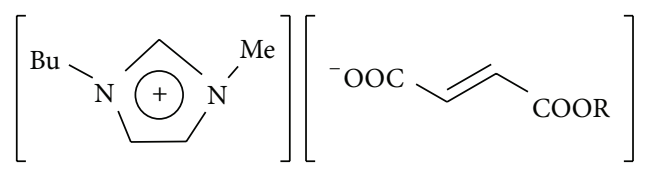

[BMIM] [MRF]

$$
\begin{array}{ll}
\mathrm{R}=\mathrm{CH}_{3} & {[\mathrm{BMIM}][\mathrm{MMF}]} \\
\mathrm{R}=\left(\mathrm{CH}_{2}\right)_{3} \mathrm{CH}_{3} & {[\mathrm{BMIM}][\mathrm{MBF}]} \\
\mathrm{R}=\left(\mathrm{CH}_{2}\right)_{7} \mathrm{CH}_{3} & {[\mathrm{BMIM}][\mathrm{MOF}]} \\
\mathrm{R}=\left(\mathrm{CH}_{2}\right)_{11} \mathrm{CH}_{3} & {[\mathrm{BMIM}][\mathrm{MDF}]}
\end{array}
$$

SCHEME 1: The structure of ILs with fumarate anion.

benzoates [25]. Unfortunately, they were found to have only limited solubility in aqueous system. To overcome these limitations, we have proposed a new class of water soluble ILs with fumarate anion. The new ILs that have $\alpha, \beta$-unsaturated carbonyl structure will be expected to have enhanced antimicrobial activity. Their structures are shown in Scheme 1.

\section{Materials and Methods}

2.1. Materials. Maleic anhydride, methanol, n-butanol, noctanol, n-dodecanol, n-chlorobutane, potassium sorbate, beef extract, and peptone were purchased from Shanghai Chemical Agent Co. (Shanghai, China). Methyl imidazole was redistilled under reduced pressure before use. The other reagents were of analytical grade and used without further purification. Synthesis of $[\mathrm{BMIM}]\left[\mathrm{BF}_{4}\right]$ was described in our previous publication [8].

2.2. Characterizations of ILs. The ${ }^{1} \mathrm{H} \mathrm{NMR}$ and ${ }^{13} \mathrm{C} \mathrm{NMR}$ spectra were obtained on a Brüker AV-400 Fourier transform NMR spectrometer. ${ }^{1} \mathrm{H}$ NMR spectra were referenced to tetramethylsilane in $\mathrm{CDCl}_{3}$. Thermal gravimetric analysis (TGA) was performed on a Netzsch TG 209F1 instrument in $\mathrm{N}_{2}$ flow with a heating speed of $10^{\circ} \mathrm{C} / \mathrm{min}$.

2.3. General Procedure for the Synthesis of ILs with Fumarate Anion. The synthesis route of ILs with fumarate anion ([BMIM][MRF]) is shown in Scheme 2.

Monoester fumarate was synthesized according to the literature methods [26].

1-Butyl-3-methylimidazolium chloride ([BMIM]Cl) was obtained by the reaction of freshly distilled methyl imidazole with a slight excess equimolar dried n-chlorobutane in a round-bottomed flask fitted with a reflux condenser for $24 \mathrm{~h}$ at $68^{\circ} \mathrm{C}$ with stirring until two phases formed. The top phase, containing unreacted starting material, was decanted, and ethyl acetate (a volume approximately equal to half that of the bottom phase) was added with thorough mixing. The ethyl acetate was decanted followed by the addition of fresh ethyl acetate, and this step was repeated twice. Washing with ethyl acetate should suffice to remove any unreacted material from the bottom phase. After the third decanting of ethyl acetate, any remaining ethyl acetate was removed by heating the bottom phase to $68^{\circ} \mathrm{C}$ and stirring while on a vacuum line. The product, $[\mathrm{BMIM}] \mathrm{Cl}$, is white crystal at room temperature.
Aqueous solution of 1-butyl-3-methylimidazolium hydroxide ([BMIM]OH) was prepared by passing the imidazolium chloride through a column filled in anion-exchange resin, as described in the literature [8].

[BMIM][MRF] was synthesized by neutralization of aqueous [BMIM] $\mathrm{OH}$ with equimolar monoester fumarate. The solution was evaporated at $50^{\circ} \mathrm{C}$ under reduced pressure to give a viscous liquid, which was then vacuum-dried at $50^{\circ} \mathrm{C}$ for $18 \mathrm{~h}$ to afford the IL product.

\subsubsection{1-Butyl-3-methylimidazolium Monomethyl Fumarate} ([BMIM][MMF]). Colorless liquid, yield 96.1\%; ${ }^{1} \mathrm{H}$ NMR $\left(400 \mathrm{MHz}, \mathrm{D}_{2} \mathrm{O}\right) \delta: 8.625$ (s, $\left.1 \mathrm{H}, \mathrm{im}-\mathrm{H}\right), 7.869$ (s, $1 \mathrm{H}$, im$\mathrm{H}), 7.824$ (s, $1 \mathrm{H}, \mathrm{im}-\mathrm{H}), 6.343-6.773$ (q, $2 \mathrm{H}, \mathrm{CH}=\mathrm{CH}), 4.071$ $\left(\mathrm{t}, 2 \mathrm{H},-\mathrm{CH}_{2}\right), 3.782\left(\mathrm{~s}, 3 \mathrm{H}, \mathrm{O}-\mathrm{CH}_{3}\right), 3.678(\mathrm{~s}, 3 \mathrm{H}$, im$\left.\mathrm{CH}_{3}\right), 1.700-1.737\left(\mathrm{~m}, 2 \mathrm{H},-\mathrm{CH}_{2}\right), 1.180-1.199\left(\mathrm{~m}, 2 \mathrm{H},-\mathrm{CH}_{2}\right)$, 0.776-0.813 (t, 3H, $\left.-\mathrm{CH}_{3}\right) ;{ }^{13} \mathrm{C}$ NMR $\left(400 \mathrm{MHz}, \mathrm{D}_{2} \mathrm{O}\right) \delta$ : $172.318,168.678,141.041,135.776,135.317,127.763,123.484$, $122.199,52.494,49.248,35.615,31.255,31.406,29.216,18.751$, 12.638 .

\subsubsection{1-Butyl-3-methylimidazolium Monobutyl Fumarate} ([BMIM][MBF]). Colorless liquid, yield 96.8\%; ${ }^{1} \mathrm{H}$ NMR (400 MHz, $\left.\mathrm{D}_{2} \mathrm{O}\right) \delta: 8.625$ (s, $\left.1 \mathrm{H}, \mathrm{im}-\mathrm{H}\right), 7.387$ (s, $\left.1 \mathrm{H}, \mathrm{im}-\mathrm{H}\right)$, 7.342 (s, 1H, im-H), 6.374-6.815 (q, 2H, CH=CH), 4.079$4.145\left(\mathrm{~m}, 4 \mathrm{H},-\mathrm{CH}_{2}\right), 3.801\left(\mathrm{~s}, 3 \mathrm{H}, \mathrm{im}-\mathrm{CH}_{3}\right), 1.713-1.786(\mathrm{~m}$, $\left.2 \mathrm{H},-\mathrm{CH}_{2}\right), 1.545-1.616\left(\mathrm{~m}, 2 \mathrm{H},-\mathrm{CH}_{2}\right), 1.175-1.345(\mathrm{~m}, 4 \mathrm{H}$, $\left.-\mathrm{CH}_{2}\right), 0.809-0.846\left(\mathrm{t}, 6 \mathrm{H},-\mathrm{CH}_{3}\right) ;{ }^{13} \mathrm{C} \mathrm{NMR}(400 \mathrm{MHz}$, $\left.\mathrm{D}_{2} \mathrm{O}\right) \delta: 172.688,168.626,140.993,128.076,123.437,122.161$, 66.834, 49.233, 35.567, 31.238, 29.876, 18.738, 18.528, 12.947, 12.610 .

2.3.3. 1-Butyl-3-methylimidazolium Monooctyl Fumarate ([BMIM][MOF]). Colorless sticky liquid, yield 93.5\%; ${ }^{1} \mathrm{H}$ NMR (400 MHz, D 2 O) $\delta: 8.653(\mathrm{~s}, 1 \mathrm{H}, \mathrm{im}-\mathrm{H}), 7.346(\mathrm{~s}, 1 \mathrm{H}$, im-H), 7.319 (s, 1H, im-H), 6.327-6.694 (q, 2H, CH=CH), $4.035\left(\mathrm{t}, 2 \mathrm{H},-\mathrm{CH}_{2}\right), 3.958\left(\mathrm{t}, 2 \mathrm{H},-\mathrm{CH}_{2}\right), 3.760(\mathrm{~s}, 3 \mathrm{H}$, $\left.\mathrm{im}-\mathrm{CH}_{3}\right), 1.496-1.681\left(\mathrm{~m}, 4 \mathrm{H},-\mathrm{CH}_{2}\right), 1.125-1.174(\mathrm{~m}, 12 \mathrm{H}$, $\left.-\mathrm{CH}_{2}\right), 0.706-0.761\left(\mathrm{~m}, 6 \mathrm{H},-\mathrm{CH}_{3}\right) ;{ }^{13} \mathrm{C} \mathrm{NMR}(400 \mathrm{MHz}$, $\left.\mathrm{D}_{2} \mathrm{O}\right) \delta: 166.862,141.073,135.860,128.168,123.574,122.116$, 64.781, 49.161, 35.669, 31.764, 31.406, 29.216, 29.103, 28.395, $25.749,22.510,18.878,13.725,12.796$.

2.3.4. 1-Butyl-3-methylimidazolium Monododecyl Fumarate ([BMIM][MDF]). Colorless sticky liquid, yield 92.8\%; ${ }^{1} \mathrm{H}$ NMR (400 MHz, D 2 ) $\delta: 8.664$ (s, $1 \mathrm{H}, \mathrm{im}-\mathrm{H}), 7.363$ (s, $1 \mathrm{H}$, im-H), 7.335 (s, 1H, im-H), 6.324-6.732 (q, 2H, CH=CH), 3.906-4.094 (m, 4H, - $\left.\mathrm{CH}_{2}\right), 3.777\left(\mathrm{~s}, 3 \mathrm{H}, \mathrm{im}-\mathrm{CH}_{3}\right), 1.690-$ $1.702\left(\mathrm{~m}, 4 \mathrm{H},-\mathrm{CH}_{2}\right), 1.169-1.211\left(\mathrm{~m}, 20 \mathrm{H},-\mathrm{CH}_{2}\right), 0.754-$ $0.803\left(\mathrm{~m}, 6 \mathrm{H},-\mathrm{CH}_{3}\right) ;{ }^{13} \mathrm{C} \mathrm{NMR}\left(400 \mathrm{MHz}, \mathrm{D}_{2} \mathrm{O}\right) \delta: 171.035$, $167.217,142.239,135.884,135.328,127.334,123.559,122.117$, $64.749,49.163,35.638,31.968,31.391,29.910,29.833,29.512$, 28.518, 25.981, 25.955, 25.895, 22.616, 18.855, 13.744, 12.769 .

2.4. Density Determination. The densities of [BMIM][MRF] were determined at room temperature $\left(25^{\circ} \mathrm{C}\right)$ by placing $1.00 \mathrm{~mL}$ of $[\mathrm{BMIM}][\mathrm{MRF}]$ in a $1.00 \mathrm{~mL}$ volumetric tube and 


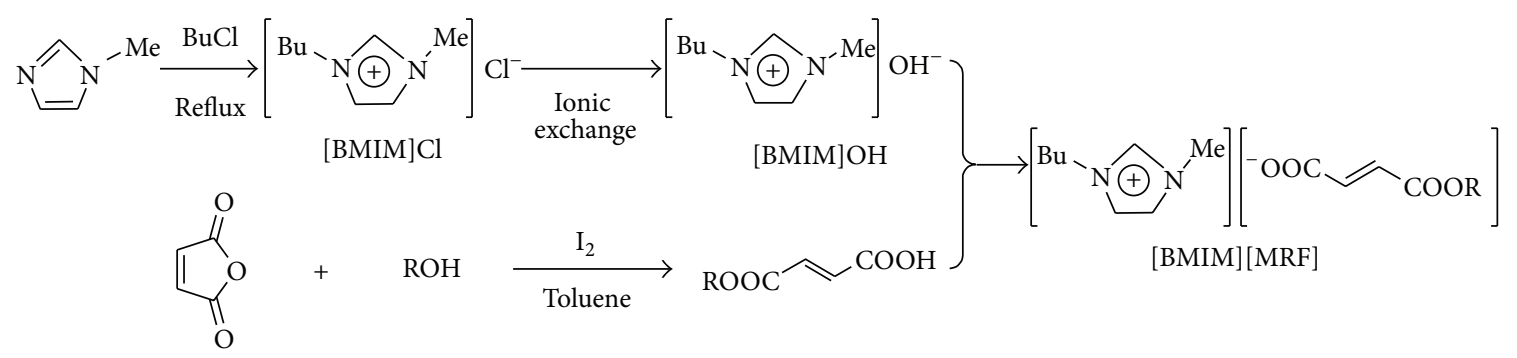

Scheme 2: Synthesis of ILs with fumarate anion.

weighing the difference. The measurements were repeated three times, and the average value is reported.

2.5. Electrical Conductivity. The electrical conductivity $(k)$ of [BMIM][MRF] was measured by a conductivity meter (Shanghai Precision \& Scientific Instrument Co., Ltd. REX Instrument Factory, model DDB-303A) at $25^{\circ} \mathrm{C}$.

2.6. Solubility Determination. All solubility determinations are carried out at the laboratory temperature in small test tubes (e.g., $100 \times 12 \mathrm{~mm}$ ) but of sufficient size to permit vigorous shaking of the solvent and the solute. Add $0.20 \mathrm{~mL}$ of [BMIM][MRF] with successive $1.00 \mathrm{~mL}$ portions of the solvent, with shaking vigorously after each addition, until $3.00 \mathrm{~mL}$ has been added. If [BMIM] [MRF] does not dissolve completely in $3.00 \mathrm{~mL}$ of the solvent, it may be regarded as insoluble in the solvent.

2.7. Preparation of Culture Media. Luria agar (LA) media consisted of yeast extract $(5 \mathrm{~g})$, tryptone $(10 \mathrm{~g}), \mathrm{NaCl}(10 \mathrm{~g})$, and agar $(15 \mathrm{~g})$, in $1000 \mathrm{~mL}$ of distilled water. For the preparation of PDA media, potato extract $(100 \mathrm{~g})$, glucose $(10 \mathrm{~g})$ and agar $(10 \mathrm{~g})$ were dissolved in $500 \mathrm{~mL}$ of distilled water. Culture media were adjusted to $\mathrm{pH} 6.0$ by addition of dilute $\mathrm{HCl}$.

2.8. Antimicrobial Test. [BMIM][MRF] was evaluated for their in vitro antibacterial activity against Gram-positive $B$. subtilis, Gram-negative E. coli, and antifungal activity against yeast $S$. cerevisiae, all of which were provided by School of Bioengineering, Jimei University. Antimicrobial activity was determined by the cylinder plate agar diffusion method. The advantages of the cylinder plate assay are (1) solution being assayed need not be sterile. (2) It was adaptable to rapid assay. (3) It was more sensitive to low dilutions than the paper disc assay [27, 28]. Inocula were prepared by transferring loopfuls of pure culture in media (LB or PDA media) followed by incubation: yeast $S$. cerevisiae was incubated in PDA media at $30^{\circ} \mathrm{C}$ and $200 \mathrm{rpm} ;$ E. coli and B. subtilis strain in LB media at $37^{\circ} \mathrm{C}$ and $200 \mathrm{rpm}$. After the absorbance at $600 \mathrm{~nm}$ of cultures reached $0.7-0.8,0.1 \mathrm{~mL}$ of the preculture suspension was inoculated into $5 \mathrm{~mL}$ fresh media.

The cylinder plate was made by putting sterilized cylinders into an agar plate. The agar plate was composed of two layers, the LA or PDA agar $(20 \mathrm{~mL})$, and was poured into $90 \mathrm{~mm} \times 20 \mathrm{~mm}$ Petri dishes as the base layer; after its solidification, $5 \mathrm{~mL}$ of the LA or PDA medium with spores was poured onto base layer. Six stainless steel cylinders of uniform size $(8 \mathrm{~mm} \times 6 \mathrm{~mm} \times 10 \mathrm{~mm})$ were placed on the surface of inoculated media. Each cylinder was filled with $120 \mu \mathrm{L}$ of reference (Potassium sorbate) solution in one plate and the same amount of [BMIM][MRF] in other plates for the assay. The compounds were dissolved in methanol. The bioassay plate was incubated at $30^{\circ} \mathrm{C}$ for $48 \mathrm{~h}$ (yeast) or at $37^{\circ} \mathrm{C}$ for $24 \mathrm{~h}$ (bacteria). The zone diameter of the growth inhibition was measured (in mm) using calipers (Trickle Brand, Shanghai Tool Corp.). All experiments were done in triplicates.

\section{Results and Discussion}

3.1. Characterization of ILs with Fumarate Anion. All the ILs prepared are airstable under ambient conditions and may be handled under normal laboratory conditions. [BMIM] [MRF] was characterized using ${ }^{1} \mathrm{H}$ and ${ }^{13} \mathrm{C}$ NMR. All the characterization data are consistent with the expected compositions and structures.

3.2. Thermal Analysis. In order to demonstrate the decomposition behavior of [BMIM] [MRF], the thermogravimetric (TG) and derivative thermogravimetric (DTG) curves are shown in Figure 1. It is seen that all studied [BMIM] [MRF], in contrast to [BMIM] Cl degrading only in one stage, are, however, rather complex. The thermal decomposition of [BMIM][MRF] seems to proceed through two main steps. The first step can be assigned to the elimination of alcohol $(\mathrm{ROH})$ resulting in the formation of anhydride ring. The percentage of mass loss in this stage increases with molecular weight of the $[\mathrm{BMIM}][\mathrm{MRF}]$. The second main step of decomposition starts at above $260^{\circ} \mathrm{C}$ which is connected with decarboxylation of anhydride rings and is overlapped with degradation of the imidazolium, when butane and imidazole fragments are liberated. The amount of residual weight at the end temperature of degradation is almost the same in all [BMIM] [MRF]. The reason for incomplete degradation of $[\mathrm{BMIM}][\mathrm{MRF}]$ is probably the thermal crosslinking induced by heating the sample during TG [29]. The thermogravimetric parameters of typical ILs are summarized in Table 1. TGA thermograms indicate that [BMIM] $[\mathrm{MRF}]$ is thermally stable up to $160^{\circ} \mathrm{C}$.

3.3. Physicochemical Properties. In addition, we have measured density, electrical conductivity, and solubility of [BMIM][MRF] (Table 2). The density of [BMIM] [MRF] 
TABLE 1: Thermogravimetric data for ILs with fumarate anion.

\begin{tabular}{|c|c|c|c|c|c|}
\hline \multirow{2}{*}{ IL } & \multicolumn{2}{|c|}{ Stage 1} & \multicolumn{2}{|c|}{ Stage 2} & \multirow{2}{*}{ Residual weight (wt\%) } \\
\hline & $\Delta T^{\mathrm{a}}\left({ }^{\circ} \mathrm{C}\right)$ & $\Delta W^{\mathrm{b}}(\mathrm{wt} \%)$ & $\Delta T^{\mathrm{a}}\left({ }^{\circ} \mathrm{C}\right)$ & $T_{\max }{ }^{\mathrm{c}}\left({ }^{\circ} \mathrm{C}\right)$ & \\
\hline [BMIM]Cl & - & - & $190-575$ & 286 & 1.1 \\
\hline [BMIM][MMF] & $110-162$ & 11.9 & $162-575$ & 243 & 12.0 \\
\hline$[\mathrm{BMIM}][\mathrm{MOF}]$ & $110-182$ & 29.1 & $182-575$ & 233 & 12.7 \\
\hline
\end{tabular}

a Temperature range.

${ }^{\mathrm{b}}$ Total weight loss percentage at the end of the step.

${ }^{\mathrm{c}}$ Temperature maximum values of DTG curves.

TABLe 2: Physical properties of ILs with fumarate anion $\left(25^{\circ} \mathrm{C}\right)$.

\begin{tabular}{|c|c|c|c|c|c|}
\hline \multirow{2}{*}{ IL } & \multirow{2}{*}{ Density $\left(\mathrm{g} \mathrm{cm}^{-3}\right)$} & \multirow{2}{*}{$k\left(\mu \mathrm{S} \mathrm{m}^{-1}\right)$} & \multicolumn{3}{|c|}{ Solubility in solvent } \\
\hline & & & $\mathrm{H}_{2} \mathrm{O}$ & $\mathrm{MeOH}$ & {$[\mathrm{BMIM}]\left[\mathrm{BF}_{4}\right]$} \\
\hline [BMIM][MMF] & 1.165 & 2171.6 & Soluble & Soluble & Soluble \\
\hline$[\mathrm{BMIM}][\mathrm{MBF}]$ & 1.147 & 951.6 & Soluble & Soluble & Soluble \\
\hline [BMIM][MOF] & 1.104 & 361.1 & Emulsion & Soluble & Soluble \\
\hline [BMIM][MDF] & 0.985 & 201.6 & Emulsion & Soluble & Soluble \\
\hline
\end{tabular}

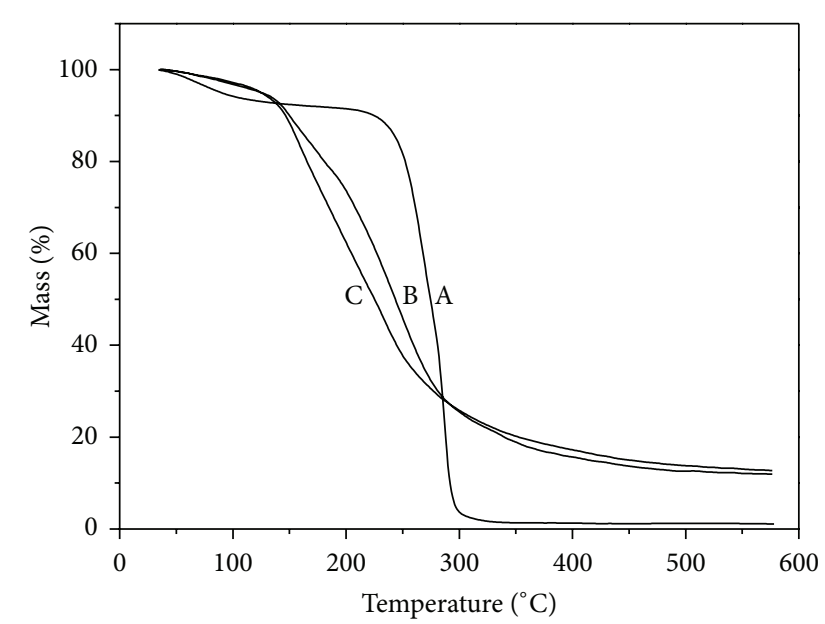

(a)

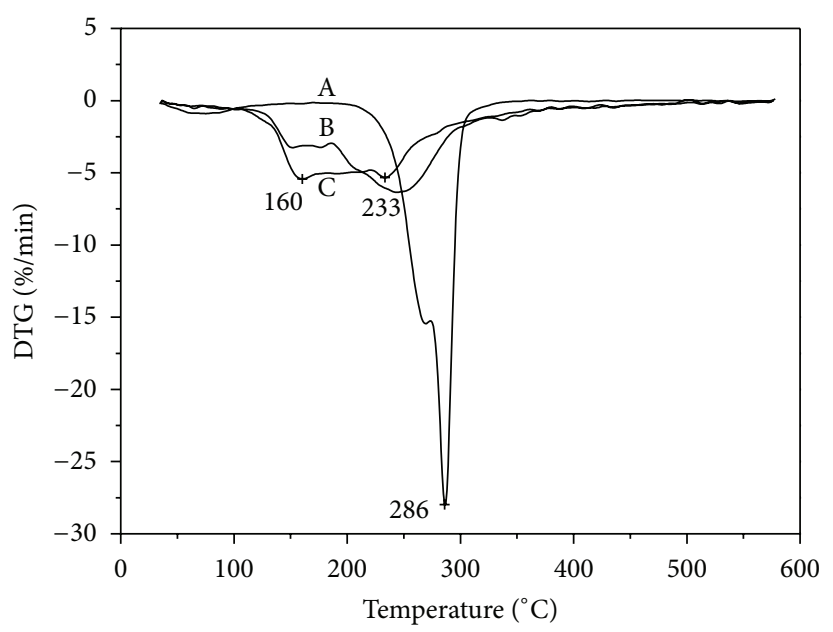

(b)

FIGURE 1: TG and DTG curves of ILs with fumarate anion. (A) [BMIM]Cl, (B) [BMIM][MMF], and (C) [BMIM][MOF].

varied in the range of $1.165-0.985 \mathrm{~g} \mathrm{~cm}^{-3}$. Here, the typical trait of ILs was preserved: increasing molecular weight was associated with a decrease in density $[10,30,31]$. On the other hand, electrical conductivity was strongly related to the structure of [BMIM][MRF]. The electrical conductivity of these ILs ranges from 201 to $2200 \mu \mathrm{S} / \mathrm{m}$ at $25^{\circ} \mathrm{C}$ (Table 2 ), which confirms their ionic nature. Addition of $\mathrm{CH}_{2}$ groups to the alkyl chain of the ester (R) decreased electrical conductivity, which is in close agreement with the literature [10]. It appears that the ionic conductivities of these ILs are mainly governed by their formula weight because the number of the ion carriers per unit volume generally decreased with increasing formula weight. [BMIM] [MRF] is soluble in water and common organic solvents at room temperature. This solubility behavior in water and organic solvents is similar to that of surfactants considering their structure. Most of quaternary ammonium-based surfactants are known to possess, in addition to interfacial activity, prominent biological activity against bacteria and fungi. Generally, anionic surfactants are only active against Gram-positive bacteria, while cationic surfactants are equally effective against Gram-positive and Gram-negative species [32].

3.4. Antimicrobial Activity. The antimicrobial properties of [BMIM][MRF] were determined with strains of Grampositive B. subtilis, Gram-negative E. coli, and yeast S. cerevisiae. Their antimicrobial activity was assessed by measuring zone diameter of the growth inhibition.

The new synthesized [BMIM][MRF] is more active than commercially available potassium sorbate (zone diameters for all tested strains $<9.2 \mathrm{~mm}$ ). ILs having other anions like chloride, oxalate, maleate, and tartrate were also screened but, as expected, showed no antimicrobial activity against the tested strains; therefore, the antimicrobial activity of $[\mathrm{BMIM}][\mathrm{MRF}]$ is due to the properties of fumarate anions.

Fumaric acid derivatives, due to their nature as an $\alpha, \beta$-unsaturated carbonyl structure, can react spontaneously 


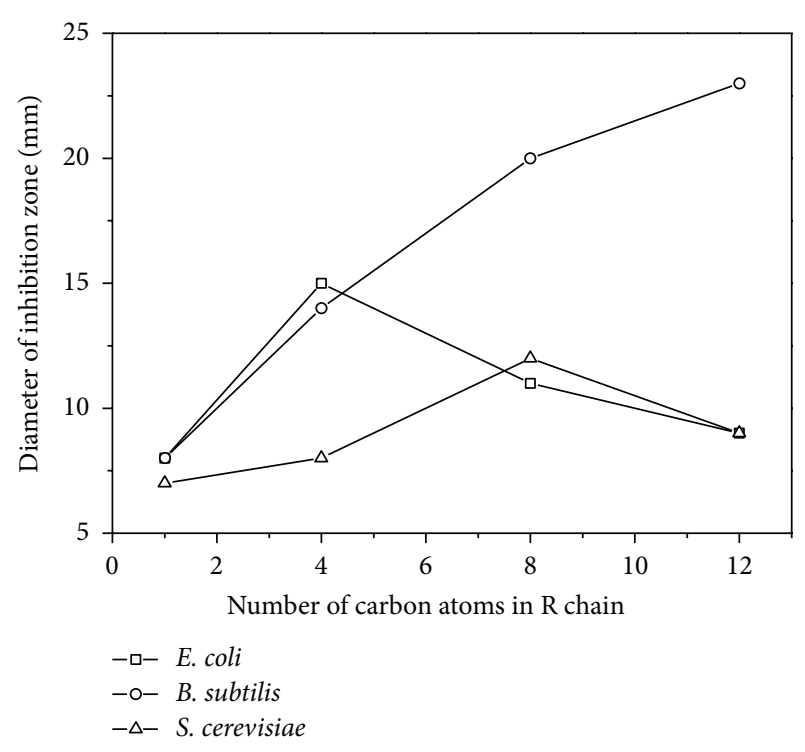

FIgURE 2: Antibacterial activity of ILs with fumarate anion. Dose: $0.6 \mathrm{mg}$ for B. subtilis, $1.2 \mathrm{mg}$ for E. coli and S. cerevisiae.

with thiols via a Michael-type addition and can react at high rates under near-physiological conditions [33]. As a result, this process makes it possible to inhibit the enzyme involved in the basic metabolism of the cell or the synthesis of important cell constituents, for example, protein synthesis, or nucleic acid synthesis [34].

As shown by Figure 2, the ILs studied are active against rods and fungi, exhibiting strong activity and wide antimicrobial action. For the studied ILs, the antimicrobial activity of [BMIM][MRF] against Gram-negative E. coli and yeast $S$. cerevisiae was dependent on chain length, showing maximal activity with alkyl group containing 4 and 8 carbon atoms, respectively. Further increases in chain length resulted in decreased activity. However, the most significant antimicrobial activity was observed in tests with $B$. subtilis (aerobe), a Gram-positive rod. Activity against B. subtilis is significantly different from those against Gram-negative $E$. coli and yeast $S$. cerevisiae indicating that no optimum activity was clear with the ILs under study here. Results reveal that these ILs show better antimicrobial activities with higher alkyl chain length against B. subtilis.

Hydrophobicity is an essential feature for antimicrobial agent membrane interactions, as it governs the extent to which the agent can partition into the lipid bilayer. Figure 2 revealed that these ILs show better antimicrobial activities with higher alkyl chain length against B. subtilis. It was reported that increasing the chain length of an n-alkyl group increases the lipophilic character of compounds, while decreasing their surface tension $[35,36]$. Increased lipophilicity would be expected to increase the affinity for the cell membrane, thereby allowing a compound to penetrate more effectively into the cell membrane, altering its nature and more effectively inhibiting bacterial growth.

But ILs with a longer chain length do not warrant a better antimicrobial activity. In the literature, maximum efficiency as antimicrobial agents was reported for alkylimidazolium and alkoxyimidazolium lactates containing 11 or 12 carbon atoms in the alkyl group [3] and for alkylimidazolium salts with 12-14 carbon atoms in the alkyl chain [9]. The optimum biological effect at a specific chain length can be attributed to the combination of several physicochemical parameters: hydrophobicity, adsorption, critical micelle concentration, aqueous solubility, and transport in the test medium, with the solubility being the limiting step for the transport [37, 38]. For the ILs here investigated, the cooperative interaction of these variables determined the maximal antimicrobial activity of [BMIM][MRF] against Gram-negative E. coli and yeast $S$. cerevisiae. Structurally, the alkyl group of fumarate tunes the lipophilicity of the IL via changing the chain length, while its carboxylate end promotes the hydrophilicity of the ILs. Therefore, the hydrophobic and hydrophilic parts of the anion provide structure affinity between the cell walls of the bacteria and the IL. Presumably, other than the nature of lipophilicity, a suitable combination of the lipophilicity and water solubility allows the ILs to have a superior antibioactivity [39].

\section{Conclusions}

Antimicrobial ILs with fumarate anion were synthesized and characterized using NMR and TGA. All the characterization data are consistent with the expected compositions and structures. The thermal decomposition of antimicrobial ILs seems to proceed through two main steps. The ILs are miscible with water and polar solvents such as methanol and dichloromethane and also with the ILs like [BMIM] $\left[\mathrm{BF}_{4}\right]$. The antimicrobial activities of the ILs are more active than commercially available potassium sorbate and are greatly affected by the alkyl chain length. The alkyl chain number correlates with their lipophilicity, while the carboxylate anion enhances their solubility in water. A balance between these two factors may play an important role in the ILs' antimicrobial activities. Successful management of current antimicrobials, and the continued development of new ones, is vital to protecting human and animal health against microbial pathogens. The significant antimicrobial properties observed in this research suggest that the ILs may have potential applications in the modern biotechnology.

\section{Abbreviations}

IL: $\quad$ Ionic liquid

[BMIM] $\left[\mathrm{BF}_{4}\right]$ : 1-Butyl-3-methylimidazolium tetrafluoroborate

[BMIM][MMF]: 1-Butyl-3-methylimidazolium monomethyl fumarate

[BMIM][MBF]: 1-Butyl-3-methylimidazolium monobutyl fumarate

[BMIM][MOF]: 1-Butyl-3-methylimidazolium monooctyl fumarate

[BMIM][MDF]: 1-Butyl-3-methylimidazolium monododecyl fumarate

[BMIM][MRF]: IL with fumarate anion

TGA: Thermal gravimetric analysis. 


\section{Conflict of Interests}

The authors do not have any possible conflict of interests with the mentioned commercial identities such as "Chemical Agent, Co. (Shanghai, China), and Shanghai Precision \& Scientific Instrument Co., Ltd. (REX Instrument 138 Factory, model DDB-303A)."

\section{Acknowledgments}

The authors acknowledge the financial supports from the Natural Science Foundation of China (51004053), the Natural Science Foundation of Fujian Province (2006J0262), and the Science Foundation of Jimei University.

\section{References}

[1] P. Wasserscheid and W. Keim, "Ionic liquids-new "solutions" for transition metal catalysis," Angewandte Chemie, vol. 39, no. 21, pp. 3773-3789, 2000.

[2] R. D. Rogers and K. R. Seddon, "Ionic liquids-solvents of the future?” Science, vol. 302, no. 5646, pp. 792-793, 2003.

[3] J. Pernak, K. Sobaszkiewicz, and I. Mirska, "Anti-microbial activities of ionic liquids," Green Chemistry, vol. 5, no. 1, pp. 5256, 2003.

[4] J. Pernak and A. Skrzypczak, "3-alkylthiomethyl-1-ethylimidazolium chlorides. Correlation between critical micelle concentrations and minimum inhibitory concentrations," European Journal of Medicinal Chemistry, vol. 31, no. 11, pp. 901-903, 1996.

[5] M. Mora-Pale, L. Meli, T. V. Doherty, R. J. Linhardt, and J. S. Dordick, "Room temperature ionic liquids as emerging solvents for the pretreatment of lignocellulosic biomass," Biotechnology and Bioengineering, vol. 108, no. 6, pp. 1229-1245, 2011.

[6] G. Ou, J. Yang, B. He, and Y. Yuan, "Buffer-mediated activation of Candida antarctica lipase B dissolved in hydroxylfunctionalized ionic liquids," Journal of Molecular Catalysis B, vol. 68, no. 1, pp. 66-70, 2011.

[7] G. Ou, L. Xu, B. He, and Y. Yuan, "Enhanced stability of charged dendrimer-encapsulated Pd nanoparticles in ionic liquids," Chemical Communications, no. 35, pp. 4210-4212, 2008.

[8] G.-N. Ou, M.-X. Zhu, J.-R. She, and Y.-Z. Yuan, "Ionic liquid buffers: a new class of chemicals with potential for controlling $\mathrm{pH}$ in non-aqueous media," Chemical Communications, no. 44 , pp. 4626-4628, 2006.

[9] D. Demberelnyamba, K.-S. Kim, S. Choi et al., "Synthesis and antimicrobial properties of imidazolium and pyrrolidinonium salts," Bioorganic and Medicinal Chemistry, vol. 12, no. 5, pp. 853-857, 2004.

[10] J. Pernak, I. Goc, and I. Mirska, "Anti-microbial activities of protic ionic liquids with lactate anion," Green Chemistry, vol. 6, no. 7, pp. 323-329, 2004.

[11] K. M. Docherty and C. F. Kulpa, "Toxicity and antimicrobial activity of imidazolium and pyridinium ionic liquids," Green Chemistry, vol. 7, no. 4, pp. 185-189, 2005.

[12] M. T. Garcia, N. Gathergood, and P. J. Scammells, "Biodegradable ionic liquids-part 2. Effect of the anion and toxicology," Green Chemistry, vol. 7, no. 1, pp. 9-14, 2005.

[13] J. Pernak, J. Feder-Kubis, A. Cieniecka-Rosłonkiewicz, C. Fischmeister, S. T. Griffin, and R. D. Rogers, "Synthesis and properties of chiral imidazolium ionic liquids with a $(1 R, 2 S, 5 R)$ (-)-menthoxymethyl substituent," New Journal of Chemistry, vol. 31, no. 6, pp. 879-892, 2007.

[14] K. Poole, "Overcoming antimicrobial resistance by targeting resistance mechanisms," Journal of Pharmacy and Pharmacology, vol. 53, no. 3, pp. 283-294, 2001.

[15] V. Roy, B. L. Adams, and W. E. Bentley, "Developing next generation antimicrobials by intercepting AI-2 mediated quorum sensing," Enzyme and Microbial Technology, vol. 49, no. 2, pp. 113-123, 2011.

[16] M. Ferrer, J. Soliveri, F. J. Plou et al., "Synthesis of sugar esters in solvent mixtures by lipases from Thermomyces lanuginosus and Candida antarctica B, and their antimicrobial properties," Enzyme and Microbial Technology, vol. 36, no. 4, pp. 391-398, 2005.

[17] A. Skrzypczak, B. Brycki, I. Mirska, and J. Pernak, "Synthesis and antimicrobial activities of new quats," European Journal of Medicinal Chemistry, vol. 32, no. 7-8, pp. 661-668, 1997.

[18] A. M. Hassan, A. M. Nassar, Y. Z. Hussien, and A. N. Elkmash, "Synthesis, characterization and biological evaluation of $\mathrm{Fe}$ (III), Co (II), Ni(II), Cu(II), and $\mathrm{Zn}$ (II) complexes with tetradentate schiff base ligand derived from protocatechualdehyde with 2-aminophenol," Applied Biochemistry and Biotechnology, vol. 167, pp. 581-594, 2012.

[19] K. P. Deepa and K. K. Aravindakshan, "Synthesis, characterization, and antifungal studies of transition metal complexes of $\omega$-bromoacetoacetanilide isonicotinylhydrazone," Applied Biochemistry and Biotechnology Part A, vol. 118, no. 1-3, pp. 283-292, 2004.

[20] M. Diz, A. Manresa, A. Pinazo, P. Erra, and M. R. Infante, "Synthesis, surface active properties and antimicrobial activity of new bis quaternary ammonium compounds," Journal of the Chemical Society, Perkin Transactions 2, no. 8, pp. 1871-1876, 1994.

[21] G. Elegir, A. Kindl, P. Sadocco, and M. Orlandi, “Development of antimicrobial cellulose packaging through laccase-mediated grafting of phenolic compounds," Enzyme and Microbial Technology, vol. 43, no. 2, pp. 84-92, 2008.

[22] J. Pernak, I. Mirska, and R. Kmiecik, "Antimicrobial activities of new analogues of benzalkonium chloride," European Journal of Medicinal Chemistry, vol. 34, no. 9, pp. 765-771, 1999.

[23] J. Joseph and K. Nagashri, "Novel copper-based therapeutic agent for anti-inflammatory: synthesis, characterization, and biochemical activities of copper(II) complexes of hydroxyflavone Schiff bases," Applied Biochemistry and Biotechnology, vol. 167, pp. 1446-1458, 2012.

[24] M. Dymicky, M. Bencivengo, R. L. Buchanan, and J. L. Smith, "Inhibition of Clostridium botulinum $62 \mathrm{~A}$ by fumarates and maleates and relationship of activity to some physicochemical constants," Applied and Environmental Microbiology, vol. 53, no. 1, pp. 110-113, 1987.

[25] M. N. Islam, "Antimicrobial agents added to animal feeds," US patent 4346118, 1982.

[26] W. Zecher and R. Merten, "Process for the preparation of fumaric acid monoesters," US patent 4515974, 1985.

[27] J. J. Gavin, "Analytical microbiology-II. The diffusion methods," Applied Microbiology, vol. 5, no. 1, pp. 25-33, 1957.

[28] W. H. Schmidt and A. J. Moyer, "Penicillin-I. Methods of assay," Journal of Bacteriology, vol. 47, pp. 199-209, 1944.

[29] M. Świtała-Zeliazkow, "Thermal degradation of copolymers of styrene with dicarboxylic acids-II: copolymers obtained by 
radical copolymerisation of styrene with maleic acid or fumaric acid," Polymer Degradation and Stability, vol. 91, no. 6, pp. 12331239, 2006.

[30] J. G. Huddleston, A. E. Visser, W. M. Reichert, H. D. Willauer, G. A. Broker, and R. D. Rogers, "Characterization and comparison of hydrophilic and hydrophobic room temperature ionic liquids incorporating the imidazolium cation," Green Chemistry, vol. 3, no. 4, pp. 156-164, 2001.

[31] L. C. Branco, J. N. Rosa, J. J. M. Ramos, and C. A. M. Afonso, "Preparation and characterization of new room temperature ionic liquids," Chemistry, vol. 8, pp. 3671-3677, 2002.

[32] Z. Baker, R. W. Harrison, and B. F. Miller, "Action of synthetic detergents on the metabolism of bacteria," The Journal of Experimental Method, vol. 73, pp. 249-271, 1941.

[33] T. J. Schmidt, M. Ak, and U. Mrowietz, "Reactivity of dimethyl fumarate and methylhydrogen fumarate towards glutathione and N-acetyl-1-cysteine-preparation of s-substituted thiosuccinic acid esters," Bioorganic and Medicinal Chemistry, vol. 15, no. 1, pp. 333-342, 2007.

[34] E. Lueck, M. Jager, and S. F. Laichena, Antimicrobial Food Additives: Characteristics, Uses, Effects, Springer, Berlin, Germany, 1997.

[35] E. Freese, C. W. Sheu, and E. Galliers, "Function of lipophilic acids as antimicrobial food additives," Nature, vol. 241, no. 5388, pp. 321-325, 1973.

[36] M. Dymicky, M. Bencivengo, R. L. Buchanan, and J. L. Smith, "Inhibition of Clostridium botulinum $62 \mathrm{~A}$ by fumarates and maleates and relationship of activity to some physicochemical constants," Applied and Environmental Microbiology, vol. 53, no. 1, pp. 110-113, 1987.

[37] C. Morán, P. Clapés, F. Comelles et al., "Chemical structure/property relationship in single-chain arginine surfactants," Langmuir, vol. 17, no. 16, pp. 5071-5075, 2001.

[38] T. J. Franklin and G. A. Snow, Biochemistry of Antimicrobial Action, Chapman and Hall, London, UK, 1985.

[39] R. T. W. Huang, K. C. Peng, H. N. Shih et al., "Antimicrobial properties of ethoxyether-functionalized imidazolium salts," Soft Matter, vol. 7, no. 18, pp. 8392-8400, 2011. 

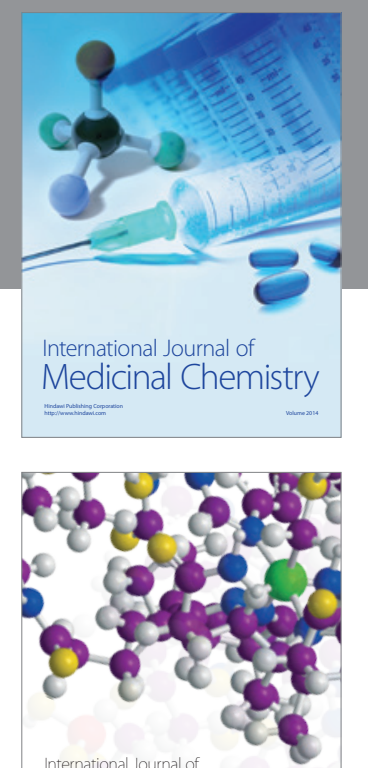

\section{Carbohydrate} Chemistry

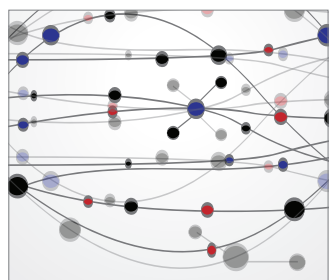

The Scientific World Journal
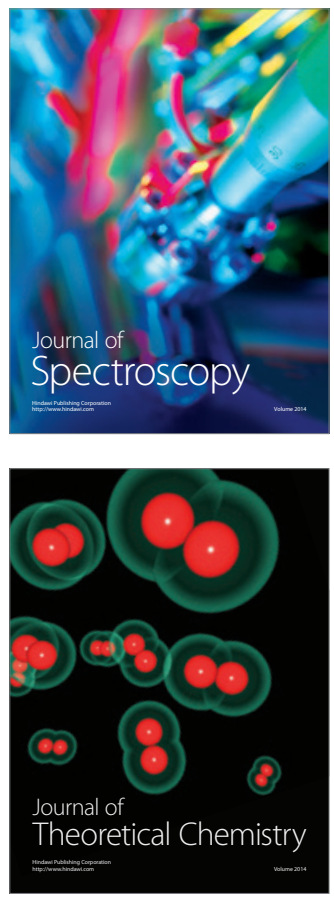
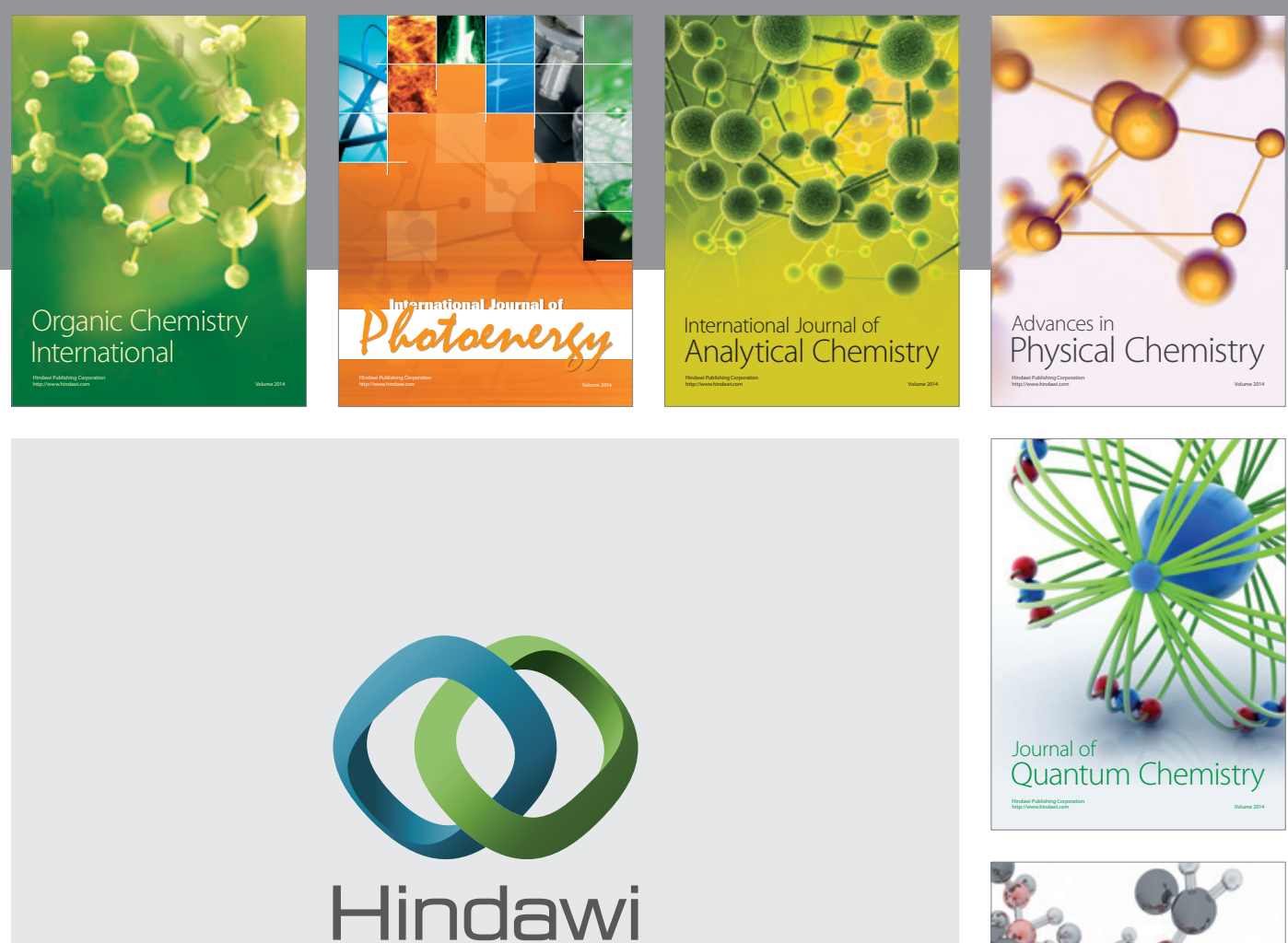

Submit your manuscripts at

http://www.hindawi.com

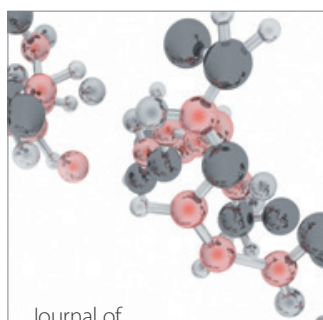

Analytical Methods

in Chemistry

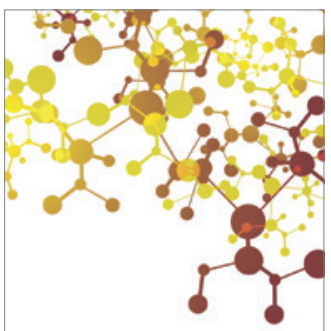

Journal of

Applied Chemistry

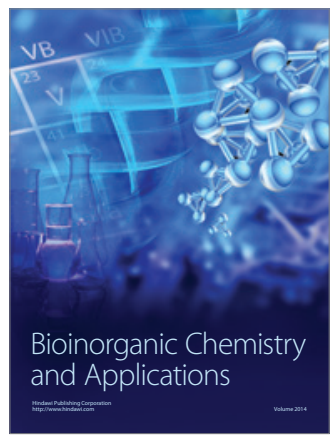

Inorganic Chemistry
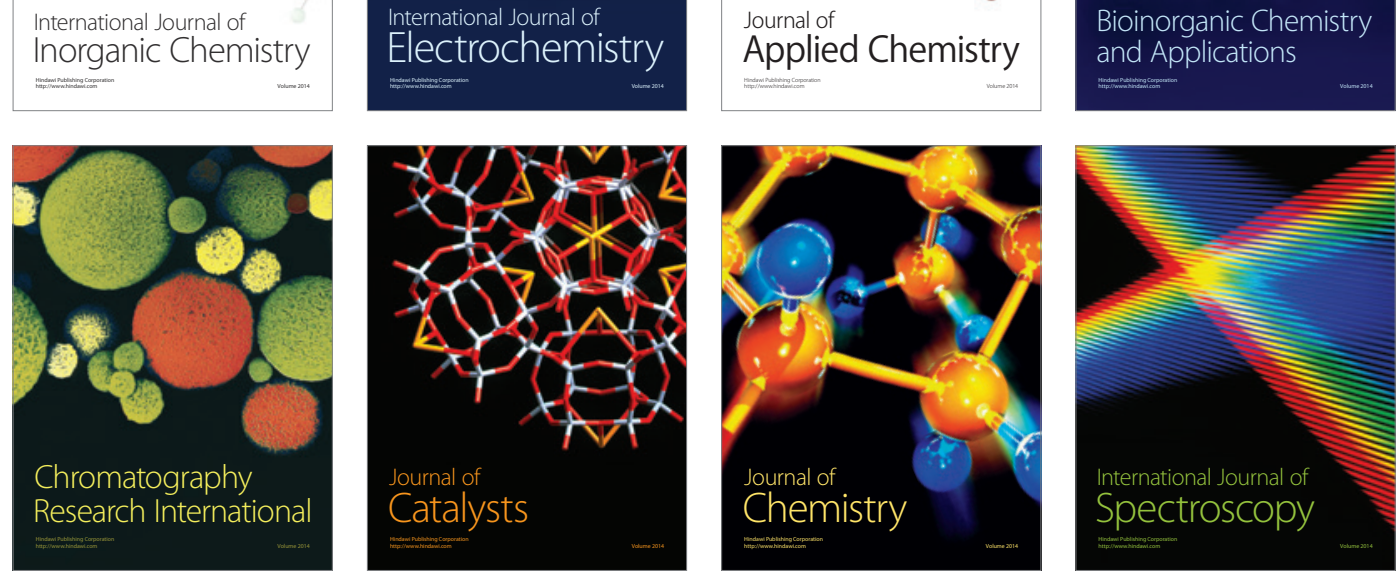